\title{
Effect of Heating Method on Microstructure and Mechanical Properties of Zircon Reinforced Aluminum Composites
}

\author{
Hudsa Majidian", Ehsan Ghasali ${ }^{a}$, Touradj Ebadzadeh ${ }^{a}$, Mansour Razavi $^{a}$ \\ ${ }^{a}$ Ceramic Division, Materials and Energy Research Centre-MERC, P.O. Box: 14155-4777, Karaj, \\ Alborz, Iran
}

Received: May 21, 2016; Revised: August 17, 2016; Accepted: October 20, 2016

\begin{abstract}
The mechanical properties and microstructure of aluminum matrix composites containing of zircon $(10,15$ and $20 \mathrm{wt} . \%)$ as a reinforcement particles and cobalt additive $(1,1.5$ and $2 \mathrm{wt} . \%)$ were investigated. The aluminum matrix composites were prepared by powder metallurgy technique and sintered in both conventional and microwave furnaces at temperatures higher than the melting point of aluminum. The results revealed that the density and mechanical strength of aluminum were increased by introducing zircon and cobalt particles. The maximum strength was obtained by adding $10 \mathrm{wt} . \%$ zircon sintered in microwave furnace at $950^{\circ} \mathrm{C}$. The phase analysis and scanning electron microscopy of sintered composites were examined and found some interesting data about intermetallic compounds.
\end{abstract}

Keywords: aluminum matrix composite, zircon particles, cobalt, microwave sintering

\section{Introduction}

Particle reinforced aluminum matrix composites have received considerable attention in aerospace and automobile industries because of high specific modulus, good wear resistance and high specific strength ${ }^{1-3}$. Aluminum matrix composites have been usually produced via powder metallurgy and casting, while achieving a homogenous distribution of reinforcement in the base alloy is more accessible with powder metallurgy in comparison with casting technique ${ }^{4-6}$. Reinforcement segregation, clustering, high localized residual porosity and poor interfacial bonding are problems found by other forming techniques ${ }^{7}$. The other composite production methods, such as spray forming, are expensive which limit their applications ${ }^{8}$. Producing net-shape components and minimizing machining process are the other advantages of using powder metallurgy. Four advantageous, known as low density, high conductivity, high toughness and low price have been made aluminum as one of the best materials in some metal matrix composites in comparison with other light metals such as magnesium ${ }^{9,10}$. In spite of all these advantages, the low strength of aluminum leads to limitation of its applications ${ }^{11}$.

Ceramic particles (e.g. $\mathrm{Al}_{2} \mathrm{O}_{3}, \mathrm{SiC}, \mathrm{TiC}$ and zircon) have been added to aluminum matrix in order to overcome its low tensile strength and attain better hardness and tolerate high temperatures ${ }^{12-16}$. Zircon is a ceramic with high chemical stability, corrosion resistance and excellent thermal shock resistance. It is cheap and available, and also is a suitable candidate for applications under elevated temperature conditions ${ }^{16,17}$.

Ravi kumar et al. ${ }^{18}$ reported the synthesis and properties of 15 wt.\% zircon particles dispersed in pure aluminum.

*e-mail: ehsan_ghasali@yahoo.com
Their composites showed a linear increase in the abrasive wear resistance with increasing zircon content in the matrix. Aluminum alloy matrix composites reinforced with zircon and alumina particles were successfully synthesized by stir casting method and results showed that hybrid reinforced composites have better hardness and tensile strength than aluminum ${ }^{19}$. Ejiofor et al. ${ }^{20}$ reported an improvement of the ultimate tensile strength, yield strength and hardness of aluminum alloy composites by adding $15 \mathrm{vol} \%$ zircon particles (size $<200 \mu \mathrm{m}$ ). The results of Abdizadeh et al. ${ }^{16,21}$ experiments also showed that the mechanical properties of aluminum-zircon composites can be optimized with $5 \mathrm{wt} \%$ zircon reinforcement at sintering temperature of $650^{\circ} \mathrm{C}$.

Several advantages such as reducing time and sintering temperature, uniform heat distribution and etc., have been reported on the application of microwave energy for processing of ceramics, metals and composites. Aluminum matrix composites reinforced with iron oxide ${ }^{23}$ and Silicon carbide $^{24}$ were prepared using microwave energy.

In the present work, the effect of zircon particles as a reinforcement and cobalt powder as an additive on the microstructure and mechanical properties of aluminum matrix was investigated. Also, the effect of different heating methods (microwave and conventional heating) on the properties of prepared composites was studied. Samples were sintered at temperatures much above the melting point of aluminum in a short time.

\section{Materials and methods}

Aluminum (MERCK Art. no. 1056 aluminum powder, 250 mesh, $99 \%$ purity), zircon ( $99.5 \%$ purity, d50=5 $\mu \mathrm{m})$ and cobalt $(99.8 \%$ purity and $5 \mu \mathrm{m}$ mean particle size) powders 
were used as raw materials. The required amounts of Al, zircon and Co powders were taken in separated batches with the compositions given in Table 1 .

Table 1: Different compositions of batches.

\begin{tabular}{lccc}
\hline Batch & $\mathrm{Al}(\mathrm{wt} . \%)$ & zircon (wt.\%) & Co (wt.\%) \\
\hline $\mathrm{A}$ & 90 & 10 & - \\
$\mathrm{B}$ & 89 & 10 & 1 \\
$\mathrm{C}$ & 83.5 & 15 & 1.5 \\
$\mathrm{D}$ & 78 & 20 & 2 \\
\hline
\end{tabular}

The batches were prepared through mixing the powder compositions determined in Table 1 using Spex (Mixer mill-8000D). In the next step, the bar shape samples with the dimension of $25 \times 5 \times 5 \mathrm{~mm}^{3}$ were compacted by uniaxial pressing at $250 \mathrm{MPa}$. Then, microwave sintering was performed at temperatures of $650^{\circ}, 750^{\circ}, 850^{\circ}$ and $950^{\circ} \mathrm{C}$ in graphite bed for 1 minute. Also, the sintering process was done at $550^{\circ}$ and $600^{\circ} \mathrm{C}$ for $\mathrm{D}$ composites. A pyrometer was used in order to depict the temperature. Samples were also sintered in a conventional furnace for 1 hour. In sample coding " $\mathrm{M}$ " and " $\mathrm{C}$ " symbols are referred to microwave and conventional heating, respectively. Numbers of 1,2 , 3 and 4 are also denoted the $650^{\circ}, 750^{\circ}, 850^{\circ}$ and $950^{\circ} \mathrm{C}$ temperatures, respectively (Table 2 ).

Table 2: Sample coding after sintering.

\begin{tabular}{lcccc}
\hline Sintering condition & A & B & C & D \\
\hline $650^{\circ} \mathrm{C}$-microwave & AM-1 & BM-1 & CM-1 & DM-1 \\
$750^{\circ} \mathrm{C}$-microwave & AM-2 & BM-2 & CM-2 & DM-2 \\
$850^{\circ} \mathrm{C}$-microwave & AM-3 & BM-3 & CM-3 & DM-3 \\
$950^{\circ} \mathrm{C}$-microwave & AM-4 & BM-4 & CM-4 & DM-4 \\
$550^{\circ} \mathrm{C}$-microwave & - & - & - & DM-550 \\
$600^{\circ} \mathrm{C}$-microwave & - & - & - & DM-600 \\
$650^{\circ} \mathrm{C}$-conventional & - & - & - & DC-650 \\
\hline
\end{tabular}

The bulk density of sintered samples was measured using the Archimedes' Principle. The bending strength of samples was examined with Santam-STm20. It was a three-point bending test followed ASTM C1161 and the rate of loading was $1 \mathrm{~mm} / \mathrm{min}$. X-ray diffraction (XRD, Philips X'Pert System) analysis was carried out to determine the phases formed in the composite samples. The microstructure of sintered samples was investigated using a scanning electron microscope (SEM, VEGA//SCAN).

\section{Results and discussion}

\subsection{Density}

Figure la shows the density of aluminum matrix composites sintered at temperatures $650^{\circ}, 750^{\circ}, 850^{\circ}$ and $950^{\circ} \mathrm{C}$ under
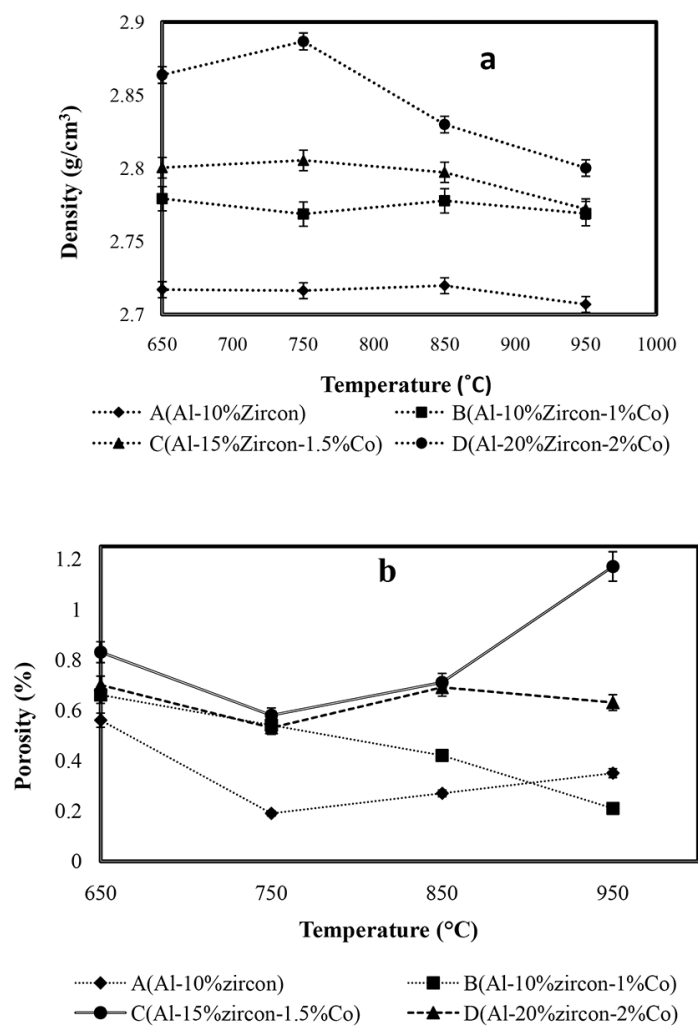

Figure 1: (a) Density and (b) porosity of $\mathrm{Al}$ composites sintered at temperatures $650^{\circ}, 750^{\circ}, 850^{\circ}$ and $950^{\circ} \mathrm{C}$ with microwave processing.

microwave irradiation. The comparison between composites $A$ and $B$ shows the effect of cobalt additive on density. As can be seen from figure 1a, using $1 \mathrm{wt} . \%$ cobalt increases the density of aluminum composites at all sintering temperatures. Furthermore, the density of composites increases with increasing the amount of zircon reinforcement from composites B to D. This is because zircon has a higher density compared to aluminum. Furthermore, by considering the error bars it seems that the density of composites (A, B and C) has been partially changed up to $850^{\circ} \mathrm{C}$ and decreased at the $950^{\circ} \mathrm{C}$. For D composite, the density increases up to $750^{\circ} \mathrm{C}$ and decreases with further increase in sintering temperature up to $950^{\circ} \mathrm{C}$. The density of composite can be influenced by the amount of component that will be changed at different sintering temperatures due to decomposition process and formation of new products. Consequently, it seems that the decrease of density at temperature of $750^{\circ}$ for $\mathrm{D}$ and $850^{\circ} \mathrm{C}$ for $\mathrm{A}$ and $\mathrm{C}$ composites can be attributed to the formation and decomposition of some components in these composites. The maximum density $\left(2.89 \mathrm{~g} / \mathrm{cm}^{3}\right)$ was achieved when $20 \mathrm{wt} . \%$ zircon and $2 \mathrm{wt} . \%$ cobalt were used in aluminum matrix sintered at $750^{\circ} \mathrm{C}$. Figure 1 shows the low amount of porosity in all aluminum composites reinforced with zircon and similar results were found by Chen et $\mathrm{al}^{24}$.

The porosity of composites was all increased by addition of zircon particles. $\mathrm{C}$ composites have the higher porosity 
than $\mathrm{A}$ and $\mathrm{B}$ composites and increasing temperature leads to the decrease of porosity in latter composites. It can be seen that the porosity decreases with the increase in sintering temperature for B composite and also with the increase in zircon content, the sintering temperature of composites increases in order to reduce porosity.

The density of aluminum based composites prepared in the present work is comparable with density reported in other works $\left(2.83 \mathrm{~g} / \mathrm{cm}^{3}{ }^{19}, 2.9 \mathrm{~g} / \mathrm{cm}^{3}{ }^{16}\right)$.

Figure 2 shows the effect of microwave and conventional heating on the density of D composites (20 wt. \% zircon and 2 wt. \% cobalt) sintered at different temperatures. It has been reported that ${ }^{21}$ the initiation of the liquid phase during sintering and densification of aluminum body can be started about $570-590^{\circ} \mathrm{C}$ and its amount will be increased at higher temperatures. With regard to above mentioned, the liquid phase sintering is expect more in composites prepared in our work and leads to the successful sintering of aluminum alloys ${ }^{1}$. The aluminum composites sintered by microwave and conventional furnaces showed comparable values in density. However, at low sintering temperatures, microwave process was found to yield higher densities rather than conventional process. DM-550, DM-600 and DM-650 composites have remarkable higher densities than DC-650 composite.

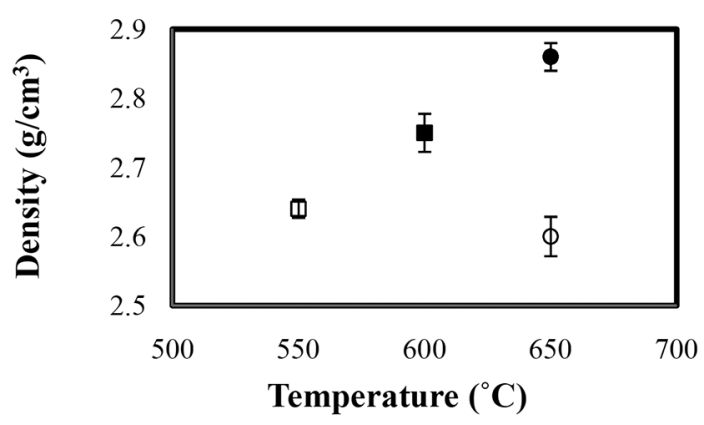

$\square D M-550 \square D M-600 \quad D M-1 \quad O D C-650$

Figure 2: Density of Al composites sintered at temperatures $550^{\circ}$, $600^{\circ}$, and $650^{\circ} \mathrm{C}$ using microwave heating and conventional furnace.

\subsection{XRD}

Figures 3 and 4 show the XRD patterns of aluminum based composites sintered in microwave (composites DM) and conventional furnaces (composite DC-650). In order to depict zircon peaks, DM composites that contain the high percentage of zircon were chosen. XRD patterns of DM-550 (figure 3) and DC-650 (figure 4) show aluminum and zircon as the main phases. Zircon was always identified by XRD analysis of aluminum-zircon composites sintered through conventional furnace in another study ${ }^{21}$. XRD of DM-series composites in the present work identified alumina, quartz and an intermetallic phase of aluminum-zirconium-silicon (m) as well as aluminum and zircon phases. Referring to

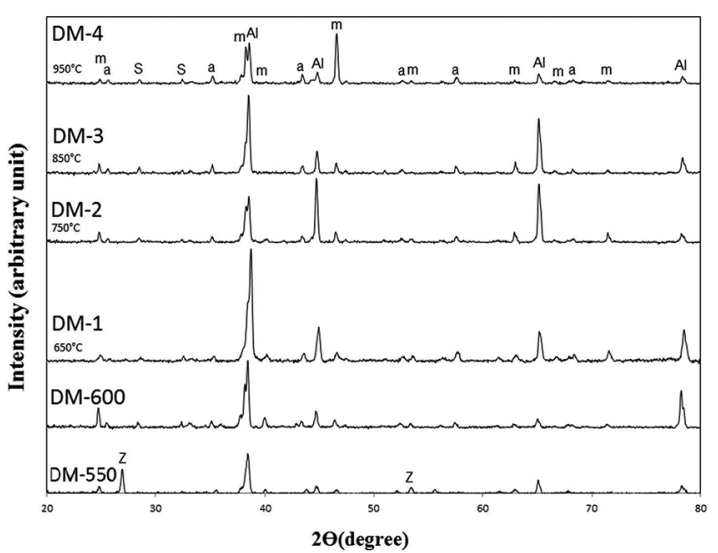

Figure 3: XRD patterns of aluminum composites containing 20 wt. $\%$ zircon and $2 \mathrm{wt} . \%$ cobalt sintered in microwave at different temperatures. Al: aluminum, a: alumina, z: zircon, s: quartz and m: aluminum-zirconium-silicon intermetallic phase.

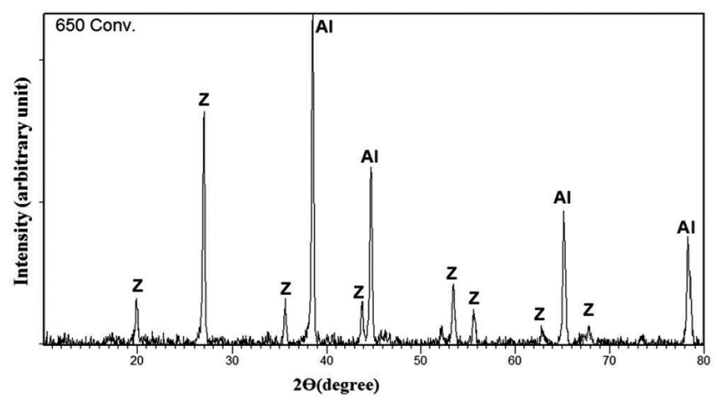

Figure 4: XRD of DC-650 composite sintered conventionally (Al: aluminum and $\mathrm{Z}$ : zircon).

JCPDS Card Number 00-014-0625, intermetallic phase of aluminum-zirconium-silicon was denoted as $\mathrm{Al} \mathrm{Si}_{\mathrm{Z}} \mathrm{Zr}$ phase. The formation of a intermetallic phase in aluminum matrix composites was reported by Banerji et $\mathrm{al}^{27}$. They reported the presence of a reaction zone including some concentrations of magnesium and silicon at the interface of zircon and matrix particles. The decomposition temperature of zircon is higher than $1600^{\circ} \mathrm{C}{ }^{28}$, however the intrinsic impurities of natural zircon can lower its decomposition temperature and play an important role on the mechanisms of its reactions ${ }^{29}$. The small amounts of impurities effect on the decomposition temperature of zircon and its kinetics and also the formation of low melting liquid phases resulting in the favored dissociation of solid silica immediately after releasing from zircon structure ${ }^{30}$. The formation of a liquid phase reaction sintering at the boundaries of the reaction grains in aluminum alloy matrix composites at $615^{\circ} \mathrm{C}$ in vacuum for $20 \mathrm{~min}$ was reported, leading to the formation of different aluminum compounds or intermetallic phases ${ }^{20}$. These intermetallic phases have been known to be the responsible of good wear properties, high abrasion resistance and good heat resistance. 
$\mathrm{XRD}$ results revealed that the dissociation of zircon in aluminum matrix occurs during microwave heating even at a low heating temperature of $600^{\circ} \mathrm{C}$ without soaking (Fig. 3 ), while it was not observed during conventional heating even at higher temperature of $650^{\circ} \mathrm{C}$ after $2 \mathrm{~h}$ of holding (Fig.4). This dissociation occurs because the increase in the local temperature around the zircon particles, leading to the formation of intermetallic phase. It is believed that in the thermal decomposition reaction process at solidliquid interface of molten aluminum and zircon particles, $\mathrm{Al}$ matrix reacts with oxygen to give $\mathrm{Al}_{2} \mathrm{O}_{3}$ and also reacts with zirconium $(\mathrm{Zr})$ and silicon $(\mathrm{Si})$ to form an intermetallic compound of Al-Zr-Si.

\subsection{Microstructure}

SEM micrographs of aluminum composites and elemental analysis of $\mathrm{A}, \mathrm{B}$ and $\mathrm{C}$ regions of figure $5 \mathrm{~b}$ are shown in figures 5 and 6, respectively. Micrographs show uniform distribution of reinforcement phases in Al metal matrix. SEM images show a clear phase contrast of different phases. High difference between the density of aluminum and two other phases can cause the adequate contrast to distinguish between three distinct phases. It is expected that the well dispersion of the phase particles in the aluminum matrix may lead to an improvement of mechanical properties of final composites. It is observed that the increase in sintering temperature from $550^{\circ} \mathrm{C}$ to $750^{\circ} \mathrm{C}$ and $950^{\circ} \mathrm{C}$ results in the increase of the grain size of the products (Figs.5(a) to 5(c)).

Elemental analysis of $\mathrm{A}, \mathrm{B}$ and $\mathrm{C}$ regions were done and given in figure 6 and table 3. High amounts of aluminum and zirconium in point $\mathrm{A}$ indicate the formation of an intermetallic phase. It is supposed that zircon particles are
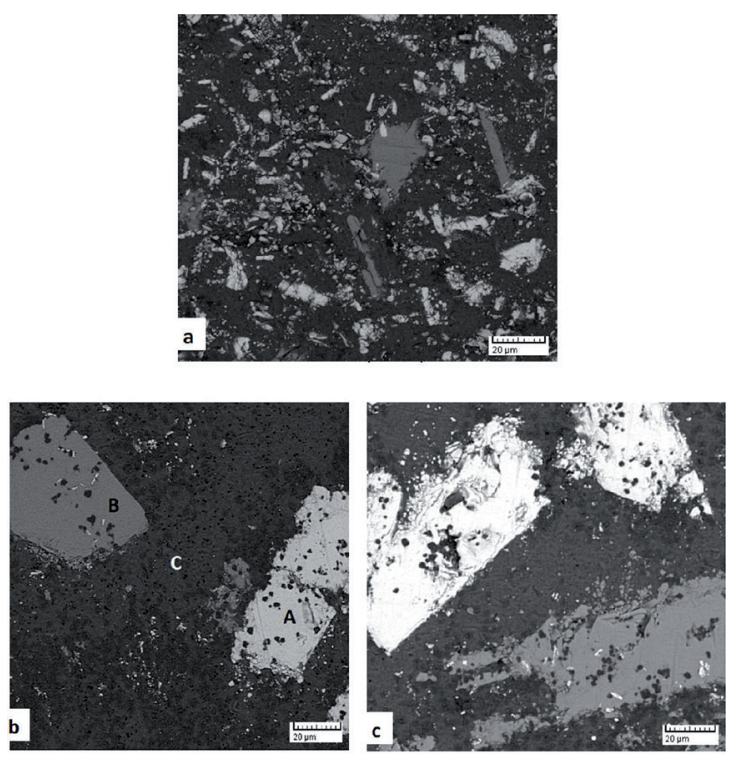

Figure 5: SEM photograph of aluminum-zircon composite (a) DM-550, (b) DM-2, (c) DM-4
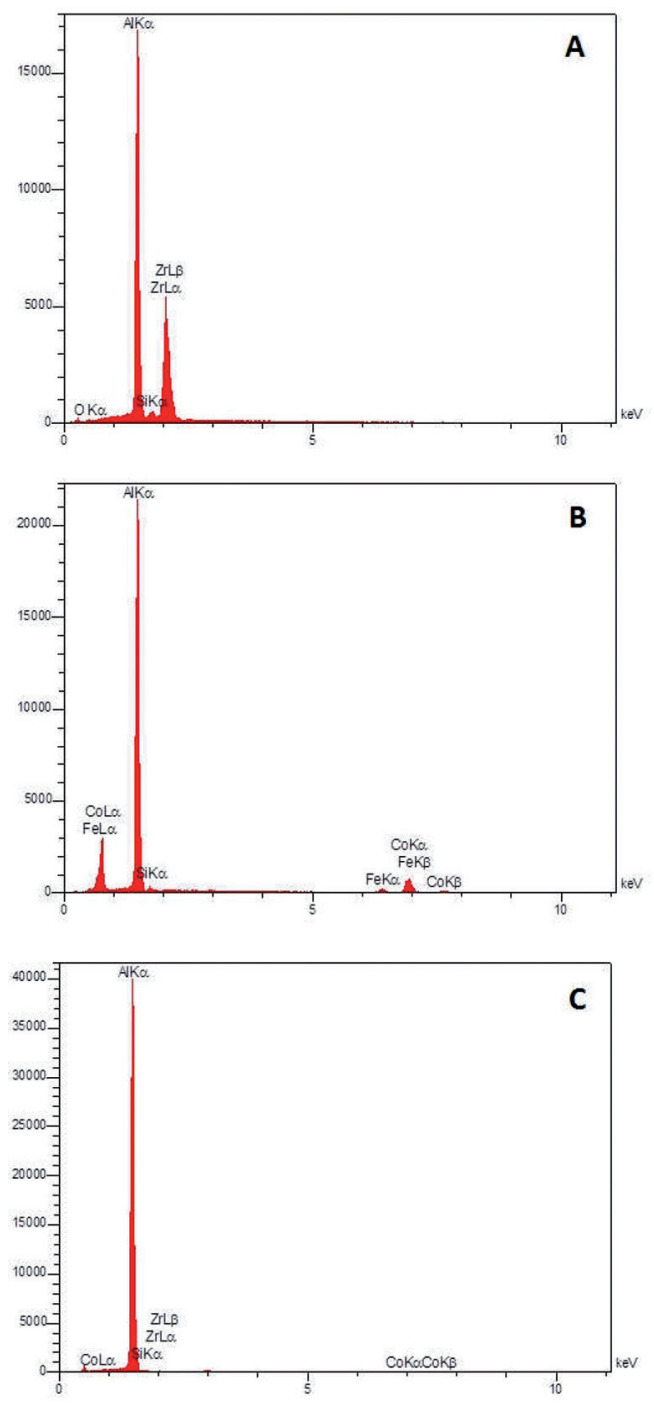

Figure 6: EDX analysis of points $\mathrm{A}, \mathrm{B}$ and $\mathrm{C}$ in figure $5 \mathrm{~b}$

Table 3: Elemental compositions of points A, B and C of figure 5

\begin{tabular}{lccc}
\hline Batch & A & B & C \\
\hline $\mathrm{O}$ & 1.68 & - & - \\
$\mathrm{Al}$ & 51.51 & 71.49 & 98.02 \\
$\mathrm{Si}$ & 1.08 & 1.28 & 1.08 \\
$\mathrm{Zr}$ & 45.73 & - & 0.66 \\
$\mathrm{Fe}$ & - & 3.94 & - \\
$\mathrm{Co}$ & - & 23.29 & 0.24 \\
\hline
\end{tabular}

completely decomposed while Al particles diffuse through them. Furthermore, B point indicates the presence of Al, $\mathrm{Si}$ and Co elements that form an intermetallic phase with another composition. The formation of intermetallic phases can be attributed to the high sintering temperature and fast sintering rate in microwave heating. In microwave process the 
rapid heating rates through skin effect via Eddy currents and suceptor lead to enhance diffusion kinetics as a result of local high temperatures ${ }^{22}$. C point indicates the aluminum matrix.

\subsection{Mechanical strength}

The mechanical strength of aluminum based composites is presented in table 4 with tolerance limits about $\pm 10 \mathrm{MPa}$. As can be seen, Zircon reinforcement and cobalt additive cause the increase of the mechanical strength of composites from series A to D. The strength values obtained by composites having the reinforcement combination of $10 \mathrm{wt} . \%$ Zircon and $1 \mathrm{wt} \%$ cobalt sintered at $750^{\circ}$ and $950^{\circ} \mathrm{C}$ were $263.9 \pm 10$ and $266.1 \pm 10 \mathrm{MPa}$, respectively. It can be seen that the presence of zircon particles in the aluminum matrix results in the increase in strength. The observed increase in strength of these composites can be attributed to the intrinsic strength and hardness of zircon. On the other hand, the liquid phase sintering can lead the successful densification and mechanical properties of aluminum alloys ${ }^{1}$.

Table 4: Mechanical strength of aluminum based composites.

\begin{tabular}{lcccc}
\hline Temperature $\left({ }^{\circ} \mathrm{C}\right)$ & 650 & 750 & 850 & 950 \\
\hline A (Al-10\%Zircon) & 213.1 & 210.8 & 231.5 & 225.1 \\
B (Al-10\%Zircon-1\%Co) & 221.7 & 263.9 & 249.7 & 266.1 \\
C (Al-15\%Zircon-1.5\%Co) & 206.6 & 250.2 & 255.4 & 216.1 \\
D (Al-20\%Zircon-2\%Co) & 232.1 & 259.9 & 223.9 & 239.2 \\
\hline
\end{tabular}

The formation of intermetallic compounds in these composites may be the other possible reason for increasing the mechanical strength. It has been reported that a chemical reaction between reinforcement phase and aluminum, and wetting of the reinforcement by aluminum and formation of an intermetallic phase are the major issues encountered in the processing of the aluminum based composites ${ }^{32}$.

The relationship between the mechanical strength of composites with sintering method is presented in table 5 . A remarkable increase of mechanical strength is observed with increasing sintering temperature. As table 5 reveals, even at lower heating temperatures, composites sintered in microwave obtained higher mechanical strength compared to those sintered in conventional furnace.

\section{Conclusions}

Aluminum based composites reinforced with zircon particles and cobalt additive were prepared successfully using microwave and conventional heating. The aluminum-Zircon composites were fabricated through powder metallurgy technique at temperatures higher than the melting point of aluminum as novel technique. The results showed that the addition of zircon particles and cobalt additive improve the densification and mechanical properties of aluminum
Table 5: Mechanical strength of aluminum composite sintered by two different methods

\begin{tabular}{lcc}
\hline Sintering temperature & Composite & strength(MPa) \\
\hline Microwave sintering-550 $\mathrm{C}$ & DM-550 & $219 \pm 7$ \\
Microwave sintering- $600^{\circ} \mathrm{C}$ & DM-600 & $217 \pm 3$ \\
Microwave sintering- $650^{\circ} \mathrm{C}$ & DM-1 & $232 \pm 9$ \\
Conventional sintering- $650^{\circ} \mathrm{C}$ & DC-650 & $156 \pm 7$ \\
\hline
\end{tabular}

matrix. Microwave heating led to the decomposition of zircon reinforcements and formation of intermetallic compounds. Density and mechanical strength of composites sintered in microwave $\left(2.86 \mathrm{~g} / \mathrm{cm}^{3}\right.$ and $266 \mathrm{MPa}$, respectively) were remarkably higher than those of composites sintered in conventional furnace $\left(2.60 \mathrm{~g} / \mathrm{cm}^{3}\right.$ and $156 \mathrm{MPa}$, respectively). The microstructure of composites showed a good dispersion of the second phase particles containing an intermetallic phase in aluminum matrix. The best mechanical results were achieved for composites sintered in microwave at $750^{\circ} \mathrm{C}$, containing 10 wt. $\%$ zircon and 1 wt. $\%$ cobalt.

\section{References}

1. Padmavathi C, Upadhyaya A, Agrawal D. Effect of sintering temperature and heating mode on consolidation of $\mathrm{Al}-7 \mathrm{Zn}-$ $2.5 \mathrm{Mg}-1 \mathrm{Cu}$ aluminum alloy. Bulletin of Materials Science. 2012;35(5):823-832.

2. Ghasali E, Alizadeh M, Ebadzadeh T, Pakseresht AH, Rahbari A. Investigation on microstructural and mechanical properties of $\mathrm{B}_{4} \mathrm{C}$-aluminum matrix composites prepared by microwave sintering. Journal of Materials Research and Technology. 2015;4(4):411-415.

3. Ghasali E, Pakseresht A, Safari-kooshali F, Agheli M, Ebadzadeh $\mathrm{T}$. Investigation on microstructure and mechanical behavior of $\mathrm{Al}-\mathrm{ZrB}_{2}$ composite prepared by microwave and spark plasma sintering. Materials Science \& Engineering: A. 2015;627:27-30.

4. Ghasali E, Pakseresht AH, Agheli M, Marzbanpour AM, Ebadzadeh T. WC-Co Particles Reinforced Aluminum Matrix by Conventional and Microwave Sintering. Materials Research. 2015;18(6):1197-1202

5. Ghasali E, Alizadeh M, Ebadzadeh T. Mechanical and microstructure comparison between microwave and spark plasma sintering of Al-B $\mathrm{B}_{4} \mathrm{C}$ composite. Journal of Alloys and Compounds. 2016;655:93-98.

6. Shirvanimoghaddam K, Khayyam H, Abdizadeh H, Karbalaei Akbari M, Pakseresht AH, Ghasali E, et al. Boron carbide reinforced aluminium matrix composite: Physical, mechanical characterization and mathematical modelling. Materials Science and Engineering: A. 2016;658:135-149.

7. Puhan D. Non-Conventional machining of Al/SiC metal matrix composite. [B.S. Thesis]. Rourkela: National Institute of Technology; 2012.

8. Kaur K, Pandey OP. Microstructural characteristics of spray formed zircon sand reinforced LM13 composite. Journal of Alloys and Compounds. 2010;503(2):410-415. 
9. Rawal SP. Metal matrix composites for space applications. JOM. 2001;53(4):14-17.

10. Swamy ARK, Ramesha A, Veeresh Kumar GB, Prakash JN. Effect of particulate reinforcements on the mechanical properties of A16061-WC and A16061-Gr MMCs. Journal of Minerals and Materials Characterization and Engineering. 2011;10(12):1141-1152.

11. Davis JR, ed. Corrosion of aluminum and aluminum alloys. $2^{\text {nd }}$ ed. Materials Park: ASM International; 1999.

12. Kerti I. Production of TiC reinforced-aluminum composites with the addition of elemental carbon. Materials Letters. 2005;59(29-30):3795-3800.

13. Tong XC, Ghosh AK. Fabrication of in situ TiC reinforced aluminum matrix composites. Journal of Materials Science. 2001;36(16):4059-4069.

14. Kheder ARI, Marahleh GS, Al-Jamea DMK. Strengthening of aluminum by $\mathrm{SiC}, \mathrm{Al}_{2} \mathrm{O}_{3}$ and $\mathrm{MgO}$. Jordan Journal of Mechanical and Industrial Engineering. 2011;5(6):533-541.

15. Ghasali E, Pakseresht A, Rahbari A, Eslami-shahed H, Alizadeh M, Ebadzadeh T. Mechanical properties and microstructure characterization of spark plasma and conventional sintering of Al-SiC-TiC composites. Journal of Alloys and Compounds. 2016;666:366-371.

16. Abdizadeh H, Ashuri M, Moghadam PT, Nouribahadory A, Baharvandi HR. Improvement in physical and mechanical properties of aluminum/zircon composites fabricated by powder metallurgy method. Materials \& Design. 2011;32(8-9):4417-4423.

17. Panwar RS, Kumar S, Pandey R, Pandey OP. Study of Nonlubricated Wear of the Al-Si Alloy Composite Reinforced with Different Ratios of Coarse and Fine Size Zircon Sand Particles at Different Ambient Temperatures. Tribology Letters. 2014;55(1):83-92.

18. Ravikumar KK, Pai BC, Satyanarayana KG, Sukumaran K. Microstructure and Properties of Pressure Die Cast Aluminium/ Zirconium Silicate Composites. Materials Transactions, JIM. 1995;36(4):565-569.

19. Rino JJ, Sivalingappa D, Koti H, Jebin VD. Properties of Al6063 MMC reinforced with zircon sand and alumina. IOSR Journal of Mechanical and Civil Engineering. 2013;5(5):72-77.

20. Ejiofo JU, Okorie BA, Reddy RG. Powder processing and properties of zircon-reinforced AI-13.5Si-2.5Mg alloy composites. Journal of Materials Engineering and Performance. 1997;6(3):326-334.
21. Abdizadeh H, Baharvandi HR, Moghaddam KS. Comparing the effect of processing temperature on microstructure and mechanical behavior of $\left(\mathrm{ZrSiO}_{4}\right.$ or $\left.\mathrm{TiB}_{2}\right) /$ aluminum composites. Materials Science and Engineering: A. 2008;498(1-2):53-58.

22. Ghasali E, Pakseresht AH, Alizadeh M, Shirvanimoghaddam K, Ebadzadeh T. Vanadium carbide reinforced aluminum matrix composite prepared by conventional, microwave and spark plasma sintering. Journal of Alloys and Compounds. 2016;688(Pt A):527-533.

23. Bayraktar E, Katundi D. Development of a new aluminium matrix composite reinforced with iron oxide $\left(\mathrm{Fe}_{3} \mathrm{O}_{4}\right)$. Journal of Achievements in Materials and Manufacturing Engineering. 2010;38(1):7-14.

24. Chen YU, Ma JJ, Guo WJ, Jiang L, Yang PY. Microwave Sintering of SiCp/Al Composite. Key Engineering Materials. 2011;492:138-141.

25. Saheb N. Spark plasma and microwave sintering of A16061 and A12124 alloys. International Journal of Minerals, Metallurgy, and Materials. 2013;20(2):152-159.

26. Okafor EG, Aigbodion VS. Effect of Zircon Silicate Reinforcements on the Microstructure and Properties of as Cast Al-4.5Cu Matrix Particulate Composites Synthesized via Squeeze Cast Route. Tribology in Industry. 2010;32(2):31-37.

27. Banerji A, Surappa MK, Rohatgi PK. Cast aluminum alloys containing dispersions of zircon particles. Metallurgical Transactions B. 1983;14(2):273-283.

28. Majidian H, Ebadzadeh T, Salahi E. Effect of SiC additions on microstructure, mechanical properties and thermal shock behaviour of alumina-mullite-zirconia composites. Materials Science and Engineering: A. 2011;530:585-590.

29. Ebadzadeh T. Porous mullite- $\mathrm{ZrO}_{2}$ composites from reaction sintering of zircon and aluminum. Ceramics International. 2005;31(8):1091-1095.

30. Bsakey A. Effect of additives on the decomposition, densification and phase analysis of zircon. [B.T. Thesis]. Rourkela: National Institute of Technology; 2011. p. 7-8.

31. Campbell FC. Structural Composite Materials. $1^{\text {st }}$ ed. Materials Park: ASM International; 2010. p. 239.

32. Tjong SC. Carbon Nanotube Reinforced Composites: Metal and Ceramics Matrices. $1^{\text {st }}$ ed. Weinheim: Wiley-VCH; 2009. p. 45-47. 